\title{
Evaluation of Bcl-2 and Bax Expression in the Heart of Diabetic Rats after Four Weelks of High Intensity Interval Training
}

\author{
Nasrin Ramezani (PhD) \\ Department of Sport Physiology, \\ Faculty of Physical Education and \\ Sport Sciences, Tehran University, \\ Tehran, Iran \\ Behnaz Vanaky (PhD) \\ Department of Physical Education and \\ Sport Sciences, Sciences and Research \\ Branch, Islamic Azad University, \\ Tehran, Iran \\ Nader Shakeri (PhD) \\ Department of Physical Education and \\ Sport Sciences, Sciences and Research \\ Branch, Islamic Azad University, \\ Tehran, Iran \\ Zahra Soltanian (MSc Student) \\ Department of Sport Physiology, \\ Department of Physical Education and \\ Sport Sciences, Sciences and Research \\ Branch, Islamic Azad University, \\ Tehran, Iran \\ Fatemeh Fakhari Rad (PhD \\ Candidate) \\ Department of Sport Physiology, \\ Department of Physical Education and \\ Sport Sciences, Sciences and Research \\ Branch, Islamic Azad University, \\ Tehran, Iran \\ Zahra Shams (PhD Candidate) \\ Department of Sport Physiology, \\ Faculty of Physical Education and \\ Sports science, Central Tehran Branch, \\ Islamic Azad University, Tehran, Iran \\ Corresponding author: Behnaz \\ Vanaky \\ Tel: +989123786165 \\ Email: Bv73ir@yahoo.com \\ Address: Azad University, Tehran, \\ Iran
}

Received: 04 Feb 2018

Revised: 02 Sep 2018

Accepted: 05 Sep 2018

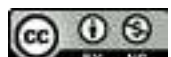

This work is licensed under a Creative Commons Attribution 4.0 License.

\section{ABSTRACT}

Background and Objectives: Diabetes is one of the most common diseases and a major risk factor for cardiovascular disease. Studies have shown that regular exercise can affect apoptosis in cardiomyocytes. The purpose of this study was to investigate the effect of high-intensity interval training on the expression of Bcl-2 and Bax as important apoptosis factors in diabetic rats.

Methods: After inducing diabetes in 20 male Wistar rats (weighing $250 \pm 1.15 \mathrm{~g}$ ), the rats were randomly divided into a control group and a training group. The training group performed high-intensity interval training five days a week for four weeks, and the control group did not perform any training. After the intervention, RNA was extracted and TCF mRNA was subjected to real time RT-PCR for measuring Bax and Bcl-2 expression in the heart tissue of diabetic rats. Data were analyzed by IBM SPSS Statistics V22 using independent t-test. P-values less than 0.05 were considered as statistically significant.

Results: The expression of Bcl-2 increased significantly and the expression of Bax decreased significantly after the four-week training intervention.

Conclusion: The high-intensity interval training can have beneficial effects on the expression of apoptotic genes in rats with type 2 diabetes.

Keywords: Bax, Bcl-2, High intensity interval training, Heart, Type 2 diabetes. 


\section{INTRODUCTION}

The prevalence of type 2 diabetes is increasing worldwide (1). Diabetes is also a major risk factor for cardiovascular disease (2). Studies have shown that cardiomyopathy and coronary atherosclerosis are caused by an abnormal diabetes-related metabolism (3). In these conditions, cardiomyocytes use fat as source of energy due to a defect in the transfer and oxidation of glucose. Accumulation of fat oxidation and abnormal metabolism byproducts causes cell death and myocardial infarction (4). Increased rate of apoptosis in pathological conditions may also cause myocardial dysfunction (5). Normally, the rate of apoptosis in myocardium is very low $(0.001$ to $0.002 \%$ ). However, this rate increases in acute and chronic heart diseases as well as in diabetes. Apoptotic messages in the early stages of apoptosis are intensified through three complex signaling pathways: 1) cytokine/Fas receptor-driven pathway, 2) mitochondrial-mediated pathway, and 3) endoplasmic reticulum $/ \mathrm{Ca}^{2+}$-driven pathway. Among these pathways, the mitochondrialmediated pathway, including the Bcl-2 family is well-characterized and believed to be critical in apoptosis regulation (6). The balance between pre-apoptotic and anti-apoptotic signals controls the fate of cells and future apoptosis programs (5). The Bcl-2 family proteins have anti-apoptotic members (such as Bcl-2 and Bcl-XL) and a subset of proapoptotic members (such as Bax, Bid and Bad) (7). The ratio between the apoptotic and antiapoptotic proteins determines cellular life cycle through mitochondrial regulation (8). It has been shown that Bax uses its $\mathrm{NH}_{2}$ terminus after moving to mitochondria to induce apoptosis. Due to this adaptation, Bax enters the outer layer of the mitochondria and subsequently apoptotic factors are released from the mitochondrial membrane (e.g., cytochrome c). It seems that Bax oligomerisation is also important in the permeabilization of the mitochondria membrane, while Bcl-2 counteracts the preapoptotic activity of Bax by preventing the oligomerisation of $\operatorname{Bax}(9,10)$. Therefore, it is important to seek strategies that can protect the heart against the risk of apoptosis.

The risk of developing cardiovascular disease and diabetes can be reduced by regular exercise $(2,11)$. Recently, researchers have shown great interest in the effect of exercise on apoptosis (6). Some studies reported that moderate-intensity exercise can reduce apoptosis $(5,6,12)$. Peterson et al. showed that nine weeks of moderate exercise training reduces the amount of Bax protein, caspase activity and DNA damage in the heart tissue of obese rats (13). Quindry et al. confirmed these findings by revealing the effect of treadmill exercise on anti-apoptotic markers in the heart tissue of rats with ischemic heart disease (14). However, Xixin et al. showed that long-term endurance exercise alters the expression of Bcl-2 and Bax in the heart, and induces apoptosis via oxidative stress (15). A study showed that low and moderate intensity training are more beneficial for type 2 diabetics compared to high intensity interval training (HIIT) (16), while another study reported that HIIT is more effective in controlling diabetes and its complications (17). Given the contradictory results of previous studies, we aimed to study the effect of HIIT on the expression of Bcl-2 and Bax in diabetic rats.

\section{METHODS}

This developmental-experimental research was performed on 20 8-week-old male Wistar rats (mean weight $250.6 \pm 15.1 \mathrm{~g}$ ) that were obtained from the Baqiyatallah Center for breeding and duplication of laboratory animals in Iran. The animals were kept at temperature of $22 \pm 2{ }^{\circ} \mathrm{C}$, humidity of $25-30 \%$, and under a 2:12 h light-dark cycle. The animals had free access to water and food. The study received approval from the ethics committee of the University of Tehran. One week after transferring rats to the laboratory, diabetes was induced and the rats were randomly divided into two weight-matched groups. Accordingly, 10 rats were included in the diabetic group and the rest were included in the control group. The control group did not perform any training during the four-week period, while all rats in the training group were subjected to a five-day a week training program for four weeks.

Diabetes was induced by intraperitoneal injection of $95 \mathrm{mg} / \mathrm{Kg}$ nicotine amide (dissolved in saline solution) and $55 \mathrm{mg} / \mathrm{Kg}$ streptozotocin (dissolved in citrate buffer solution) (18). In order to confirm diabetes, five days after the injections, a drop of blood was taken from the tail of the animals and placed on a glucometric strip. A blood glucose 
level of $>126 \mathrm{mg} / \mathrm{dl}$ indicated diabetes (19). The rats were also weighed weekly using a digital scale. The rats were anesthetized with ketamine $(90 \mathrm{mg} / \mathrm{Kg})$ and zylasein $(10 \mathrm{mg} / \mathrm{Kg})$ 48 hours after the last training session, and biopsy specimens were taken from the hearts. The heart muscle (after isolation) and amount of food consumed were also weighed using a digital scale (Sartorius, Germany) with sensitivity of $0.1 \mathrm{~g}$.

Exercise started when the rats were 17 weeks old. The training group performed HIIT for four weeks, five days a week (Table 1). The frequency of training was observed during the intervention; the rats trained on Saturdays, Sundays, Tuesdays, Wednesdays and Thursdays and rested on Mondays and Fridays. During each training session, the rats performed 10 repetitions of 1 minute with treadmill running at $30 \mathrm{~m} / \mathrm{min}$ and 2 minutes of rest between the integrals. They also performed 5 minutes of warm up and 5 minutes of cool down at $10 \mathrm{~m} / \mathrm{min}$ at the beginning and the end of each training session, respectively. The treadmill speed reached $55 \mathrm{~m} / \mathrm{min}$ in the last week of training (21).

Twenty $\mathrm{mg}$ of heart tissue were crushed by scalper and transferred to a microtube (22). RNA was extracted from the heart tissue using the RNeasy Protect Mini Kit (QIAGEN) according to the manufacturer's instructions.
Optical density was measured by a NanoDrop spectrophotometer to assess the extracted RNA concentration for cDNA preparation.

Real time RT-PCR of TCF mRNA was performed using the Rotor-Gene 6000 realtime rotary analyzer and the One-Step SYBR PrimeScript RT-PCR Kit (Takara BIO Inc., Japan). Melting curve analysis was performed at the end of the PCR cycle to determine the validity of the expected PCR products. Thermal cycling conditions were as follows: $42{ }^{\circ} \mathrm{C}$ for 20 minutes, $95^{\circ} \mathrm{C}$ for 2 minutes, 40 cycles at $94{ }^{\circ} \mathrm{C}$ for 10 seconds, and $60{ }^{\circ} \mathrm{C}$ for 40 seconds. To study the properties of primers (Table 3), temperatures of 50 to $99{ }^{\circ} \mathrm{C}$ were used to obtain melting curve. RNA Polymrasell was used as the control for determining gene expression. Reactions' cycle thresholds (CT) were extracted and recorded using the Real Time-PCR software. The $\Delta \Delta C T$ method was used for quantification of TCF mRNA expression.

Data were analyzed using IBM SPSS Statistics V22. The Shapiro-Wilk test confirmed the normal distribution of all data. Descriptive statistics including mean and standard error of the mean were used to describe the findings. Independent t-test was used to compare differences in the mean of variables between the two groups. The statistical significance level was set at 0.05 .

Table1- Details of the high-intensity interval-training program used in the study

\begin{tabular}{ccccc}
\hline Week & First & Second & Third & Fourth \\
\hline Speed $(\mathbf{m} / \mathbf{m i n})$ & $\mathbf{3 0}$ & $\mathbf{4 0}$ & $\mathbf{5 5}$ & $\mathbf{5 5}$ \\
Duration $(\mathrm{min})$ & 1 & 1 & 1 & 1 \\
Repeat & $\mathbf{1 0}$ & $\mathbf{1 0}$ & $\mathbf{1 0}$ & $\mathbf{1 0}$ \\
Rest/min & $\mathbf{2}$ & $\mathbf{2}$ & $\mathbf{2}$ & $\mathbf{2}$ \\
\hline
\end{tabular}

Table 2-Sequence of the primers used in the study

\begin{tabular}{|c|c|c|}
\hline Genes & Primer sequence & Code Number \\
\hline \multirow[t]{2}{*}{ Bax } & For: ACAGGGTTTCATCCAGGATCGAG & NM-017059.2 \\
\hline & AGCTCCATGTTGTTGTCCAGTTC & \\
\hline \multirow[t]{2}{*}{ Bcl-2 } & For: GGATTGTGGCCTTCTTTGAGTTC & NM-016993.1 \\
\hline & Rev: AGAGCGATGTTGTCCACCAG & \\
\hline \multirow[t]{2}{*}{ GAPDH } & For: AAGTTCAACGGCACAGTCAAGG & NM-017008.4 \\
\hline & Rev: CATACTCAGCACCAGCATCACC & \\
\hline
\end{tabular}

\section{RESULTS}

Diabetes caused a significant increase in the mean weight of rats in both groups after two months $(\mathrm{P}=0.001)$ (Table 3). After the four-week training program, the mean weight of rats in the training group decreased significantly compared to the control group.
The weight of the heart muscle was significantly higher in the training group than in the control group $(\mathrm{P}=0.000)$. The expression of $\operatorname{Bax}(\mathrm{P}=0.002)$ decreased significantly, while the expression of $\mathrm{Bcl}-2 \quad(\mathrm{P}=0.009)$ increased significantly in the training group. 


\section{DISCUSSION}

Diabetes is one of the main causes of cardiovascular disease. The prevalence of diabetes in patients with heart disease has been reported to be three times higher (23). Different pharmacological and nonpharmacological interventions have been proposed for the prevention and treatment of diabetes. Recently, regular physical activity was introduced as an effective method for the prevention and treatment of type 2 diabetes (24). In this regard, most studies have investigated the therapeutic effects of continuous low-intensity training (such as walking, jogging and cycling) for 30 minutes or more in a single session. However, this method of training has not been well established. On the other hand, HIIT may be more effective in controlling blood glucose in diabetic patients (24). Studies have shown that this type of training improves insulin sensitivity in the liver and muscle tissue (25). However, the subcellular mechanisms involving this effect are not well understood in patients at risk of metabolic disorders and chronic heart disease. In this study, we investigated the effects of HIIT on the expression of Bcl-2 and Bax genes in the heart tissue of type 2 diabetic rats.

In the present study, the induction of diabetes increased the weight of rats, which was continued until the end of the intervention, indicating that diabetes induces weight gain and obesity in rats. After the four-week training intervention, the weight of rats in the training group was significantly lower than the control group. Bcl-2 and Bax gene expression increased and decreased, respectively in the heart tissue of diabetic rats. Increased expression of Bax and decreased expression of Bcl-2 in endothelial cells is thought to be associated with an increase in glucose and A1C levels (26). Molly showed that hyperglycemia increases p53 expression and decreases glucose transport regulators, thus stimulating mitochondrial-mediated apoptosis (27). Similar to our findings, many studies have shown that physical activity modifies apoptosis factors $(6,28)$. In a study by Jafari et al., 12 weeks of treadmill running at speed of $24-33 \mathrm{~m} / \mathrm{min}$ (15\% slope) for 10-60 minutes decreased $\mathrm{Bcl}-2 / \mathrm{Bax}$ ratio significantly (6), which is in line with our findings. Inconsistent with our study, they found no significant difference in Bcl-2 expression between the training group and the control group. This could be attributed to the difference in the intensity and type of training used in the two studies. A study claimed that only HIIT could effectively regulate superoxide dismutase activity in ventricular myocardial infarction (29). Another study showed that HIIT might lower the level of superoxide anion radical and malondialdehyde, which could prevent apoptosis and cell death. Lu et al. studied the effects of HIIT and moderate-intensity aerobic training on apoptosis, oxidative stress and myocardial metabolism of rats. They found that only HIIT reduced oxidative stress by lowering levels of malondialdehyde and increasing levels of superoxide dismutase and glutathione peroxidase. In addition, Marefati et al. reported that moderate-intensity interval training could improve cardiac function indices and prevent cell death by reducing $\mathrm{TNF} \alpha$ levels in cardiac tissue (30).

\section{CONCLUSION}

Our results suggest that HIIT can have similar effects to aerobic exercise in lowering oxidative and inflammatory factors and modifying amount of apoptotic and antiapoptotic proteins. This type of exercise can also reduce blood glucose level and the subsequent oxidation and inflammation in diabetic patients, thus reducing the risk of diabetic complications. We recommend this type of exercise as an effective method for preventing cell death in the heart tissue of patients with type 2 diabetes.

\section{ACKNOWLEDGMENTS}

This article has been derived from a $\mathrm{PhD}$ dissertation (code 2299486) supported by the Tehran University. The authors would like to thank Dr. Gaeeni who led us through this research.

\section{CONFLICT OF INTEREST}

All contributing authors declare that there is no conflict of interest. 


\section{REFERENCES}

1. Sjöros TJ, Heiskanen MA, Motiani KK, Löyttyniemi E, Eskelinen JJ, Virtanen KA, et al. Increased insulinstimulated glucose uptake in both leg and arm muscles after sprint interval and moderate-intensity training in subjects with type 2diabetes and pre diabetes. Scand $\mathrm{J}$ Med Sci Sports. 2018; 28(1): 77-87. doi: 10.1111/sms.12875.

2. Hopps E, Canino B, Caimi G. Effects of exercise on inflammation markers in type 2 diabetic subjects. Acta diabetologica. 2011; 48(3):183-9.

3. Grundy SM, Benjamin IJ, Burke GL, Chait A, Eckel RH, Howard BV, et al. Diabetes and cardiovascular disease: a statement for healthcare professionals from the American Heart Association. Circulation. 1999; 100(10): 1134-46.

4. Shizukuda Y, Reyland ME, Buttrick PM. Protein kinase $C-\delta$ modulates apoptosis induced by hyperglycemia in adult ventricular myocytes. Am J Physiol Heart Circ Physiol. 2002; 282(5): H1625-34.

5. Santana ET, Serra AJ, Silva Junior JA, Bocalini DS, Barauna VG, Krieger JE, Tucci PJ. Aerobic exercise training induces an anti-apoptotic milieu in myocardial tissue. Motriz: Revista de Educação Física. 2014; 20(2):233-8.

6. Jafari A, Pourrazi H, Nikookheslat S, Baradaran B. Effect of Exercise Training on Bcl-2 and Bax Gene Expression in the Rat Heart. Gene, Cell and Tissue. 2015; 2(4): e32833. DOI: $10.17795 /$ gct-32833.

7. Kwak HB, Song W, Lawler JM. Exercise training attenuates age-induced elevation in $\mathrm{Bax} / \mathrm{Bcl}-2$ ratio, apoptosis, and remodeling in the rat heart. The FASEB Journal. 2006; 20(6): 791-3.

8. Hengartner MO. The biochemistry of apoptosis. Nature. 2000; 407(6805): 770-6.

9. Favaloro B, Allocati N, Graziano V, Di Ilio C, De Laurenzi V. Role of apoptosis in disease. Aging (Albany NY). 2012; 4(5): 330-49.

10. Kwak HB. Effects of aging and exercise training on apoptosis in the heart. J Exerc Rehabil. 2013; 9(2): 2129. doi: 10.12965/jer.130002.

11. Babraj JA, Vollaard NB, Keast C, Guppy FM, Cottrell G, Timmons JA. Extremely short duration high intensity interval training substantially improves insulin action in young healthy males. BMC endocrine disorders. 2009; 9(1): 3 .

12. McMillan EM, Graham DA, Rush JW, Quadrilatero J. Decreased DNA fragmentation and apoptotic signaling in soleus muscle of hypertensive rats following 6 weeks of treadmill training. J Appl Physiol (1985). 2012; 113(7): 1048-57. doi: 10.1152/japplphysiol.00290.2012.

13. Peterson JM, Bryner RW, Sindler A, Frisbee JC, Alway SE. Mitochondrial apoptotic signaling is elevated in cardiac but not skeletal muscle in the obese Zucker rat and is reduced with aerobic exercise. J Appl Physiol (1985). 2008; 105(6): 1934-43. doi: 10.1152/japplphysiol.00037.2008.

14. Quindry JC, Miller L, McGinnis G, Kliszczewicz B, Irwin JM, Landram M, et al. Ischemia reperfusion injury, KATP channels, and exercise-induced cardioprotection against apoptosis. Journal of Applied Physiology. 2012; 113(3): 498-506.
15. LI X, LU J, WU W. Effect of Long-term Endurance Exercise on Cardiac Apoptosis. Journal of Mianyang Normal University. 2009; 11:031.

16. Hansen D, Dendale P, Jonkers RA, Beelen M, Manders RJ, Corluy L, et al. Continuous low-to moderate-intensity exercise training is as effective as moderate-to high-intensity exercise training at lowering blood HbAlc in obese type 2 diabetes patients. Diabetologia. 2009; 52(9):1789-97.

17. Dunstan DW, Daly RM, Owen N, Jolley D, De Courten M, Shaw J, et al. High-intensity resistance training improves glycemic control in older patients with type 2 diabetes. Diabetes care. 2002; 25(10):1729-36.

18. Pierre W, Gildas AJ, Ulrich MC, Modeste WN, azTélesphore Benoît N, Albert K. Hypoglycemic and hypolipidemic effects of Bersama engleriana leaves in nicotinamide/streptozotocin-induced type 2 diabetic rats. BMC Complement Altern Med. 2012; 12(1): 264. doi: 10.1186/1472-6882-12-264.

19. Skovs $\varnothing$ S. Modeling type 2 diabetes in rats using high fat diet and streptozotocin. J Diabetes Investig. 2014; 5(4): 349-358.

20. Kumar AH, Clover AJ. Intraperitoneal coadministration of low dose urethane with xylazine and ketamine for extended duration of surgical anesthesia in rats. Lab Anim Res. 2015; 31(4): 174-9. doi: 10.5625/lar.2015.31.4.174.

21. Hoshino D, Yoshida Y, Kitaoka Y, Hatta H, Bonen A. High-intensity interval training increases intrinsic rates of mitochondrial fatty acid oxidation in rat red and white skeletal muscle. Appl Physiol Nutr Metab. 2013; 38(3): 326-33. doi: 10.1139/apnm-2012-0257.

22. Gaeini AA, Shafiei Neek L, Choobineh S, Baghaban Eslaminejad M, Satarifard S, Sayahpour FA, et al. Preconception endurance training with voluntary exercise during pregnancy positively influences on remodeling markers in female offspring bone. $\mathrm{J}$ Matern Fetal Neonatal Med. 2016; 29(22): 3634-40. doi: 10.3109/14767058.2016.1140140.

23. Gordon LA, Morrison EY, McGrowder DA, Young $\mathrm{R}$, Fraser YT, Zamora EM, et al. Effect of exercise therapy on lipid profile and oxidative stress indicators in patients with type 2 diabetes. BMC Complement Altern Med. 2008; 8: 21. doi: 10.1186/1472-6882-8-21.

24. Little JP, Gillen JB, Percival ME, Safdar A, Tarnopolsky MA, Punthakee Z, et al. Low-volume highintensity interval training reduces hyperglycemia and increases muscle mitochondrial capacity in patients with type 2 diabetes. J Appl Physiol (1985). 2011; 111(6): 1554-60. doi: 10.1152/japplphysiol.00921.2011.

25. Hood MS, Little JP, Tarnopolsky MA, Myslik F, Gibala MJ. Low-volume interval training improves muscle oxidative capacity in sedentary adults. Med Sci Sports Exerc. 2011; 43(10):1849-56. doi: 10.1249/MSS.0b013e3182199834.

26. Hasnan J, Yusoff MI, Damitri TD, Faridah AR, Adenan AS, Norbaini TH. Relationship between apoptotic markers (Bax and Bcl-2) and biochemical markers in type 2 diabetes mellitus. Singapore medical journal. 2010; 51(1):50-5. 
27. Moley KH. Hyperglycemia and apoptosis: mechanisms for congenital malformations and pregnancy loss in diabetic women. Trends in Endocrinology \& Metabolism. 2001; 12(2):78-82.

28. Campbell KL, McTiernan A, Li SS, Sorensen BE, Yasui Y, Lampe JW, et al. Effect of a 12-month exercise intervention on the apoptotic regulating proteins Bax and Bcl-2 in colon crypts: a randomized controlled trial. Cancer Epidemiol Biomarkers Prev. 2007; 16(9): 176774.
29. Powers SK, Criswell DA, Lawler JO, Martin DA, Lieu FK, Ji LL, Herb RA. Rigorous exercise training increases superoxide dismutase activity in ventricular myocardium. Am J Physiol. 1993; 265(6 Pt 2): H2094-8. 30. Marefati H, Aminizadeh S, Najafipour H, Dabiri S, Shahouzehi B. The Effects of Moderate-Intensity Interval Training on the Resistance to Induced Cardiac Ischemia in Adult Male Rats. Qom Univ Med Sci J. 2016: 10(4): 19. 